\title{
TENSILE BEHAVIOR OF WELDED TEE END CONNECTION FOR CIRCULAR HOLLOW MEMBERS
}

\author{
Vittorio Nascè ${ }^{1}$ and Francesco Tondolo, ${ }^{2, *}$ \\ ${ }^{1}$ Full Professor, Politecnico di Torino, Department of structural and Geotechnical Engineering, \\ corso Duca degli Abruzzi, 24, 10129, Torino, Italy \\ ${ }^{2, *}$ Research Assistant, Politecnico di Torino, Department of structural and Geotechnical Engineering, \\ corso Duca degli Abruzzi, 24, 10129, Torino, Italy \\ *(Corresponding author: E-mail: francesco.tondolo@polito.it)
}

Received: 8 August 2010; Revised: 23 September 2010; Accepted: 2 October 2010

\begin{abstract}
The structural behavior of welded tee end connections used for circular hollow sections (CHS), depends on the number and the position of the tee webs. International specifications, such as ANSI/AICS and CIDECT Design Guide, provide design rules for joints made with one or two parallel tee webs, whereas the use of cross tee webs is not taken into consideration. However, the performance of such extensively employed connections cannot directly be referred to that of single tee web connection, as confirmed by the uniaxial tensile tests presented in this paper. A numerical model, based on a nonlinear Finite Element approach, is also introduced to show the influence of some geometrical parameters on the structural efficiency of the joints. As a result, a possible extension of the current design rules for CHS connections is also suggested.
\end{abstract}

Keywords: Circular Hollow Section, Welded Tee End Connection, Uniaxial Tensile Test, FEM Analysis, Code Formulation

\section{INTRODUCTION}

The design of connections has always been a key point for steel constructions; during the recent years design codes have addressed an increasing attention on the design rules. The best choice is generally a compromise among architectural, static and constructive requirements. In the case of plane and spatial steel truss structures, circular hollow sections (CHS) are frequently connected by joints hidden inside the element [1]. Possible connections for CHS in tension are described in the Chapter 8 of the CIDECT Design Guide [2] (section "Bolted joints") and are reported in Figure 1.

The first two connections, illustrated in Figures $1 \mathrm{a}$ and $1 \mathrm{~b}$ present respectively one or two parallel webs welded to a cap plate, which is connected to the tube by a fillet weld. Conversely, Figure 1c shows a different connection. It consists of a slotted end connection and a gusset plate welded to the tube by means of a corner weld. For this connection all the design rules reported in International Specifications are based on a consolidated literature [3-5]. From the structural point of view it is certainly more efficient but also more expensive than the connections showed in Figures $1 \mathrm{a}$ and $1 \mathrm{~b}$.

Several tests performed on the welded tee end connections depicted in Figure 1a can be found in the current literature [6-7]. In these works, tube and cap plate are generally joined with a fillet weld. They are designed by assuming the presence of a stress diffusion zone between tube and tee web, even if high tensile stresses are localized in the zone where tube, cap plate and tee web converge. Starting from each face of the tee web, stresses are spread into the cap plate (with an angle $\alpha$ ) and produce dispersed effective load width $1_{\mathrm{e}}$ on the tube (see Figure 2a). In the CIDECT Design Guide [2], a similar load diffusion is assumed for designing the tee web $\left(l_{d}=\right.$ dispersed effective load width on the tee web). 

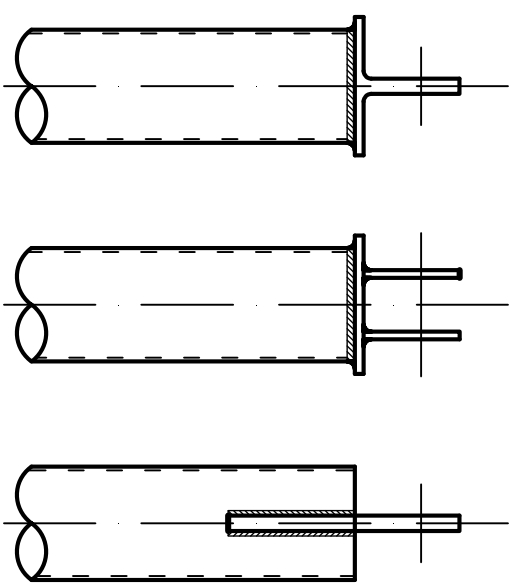

Figure 1. Bolted End Connections [2]
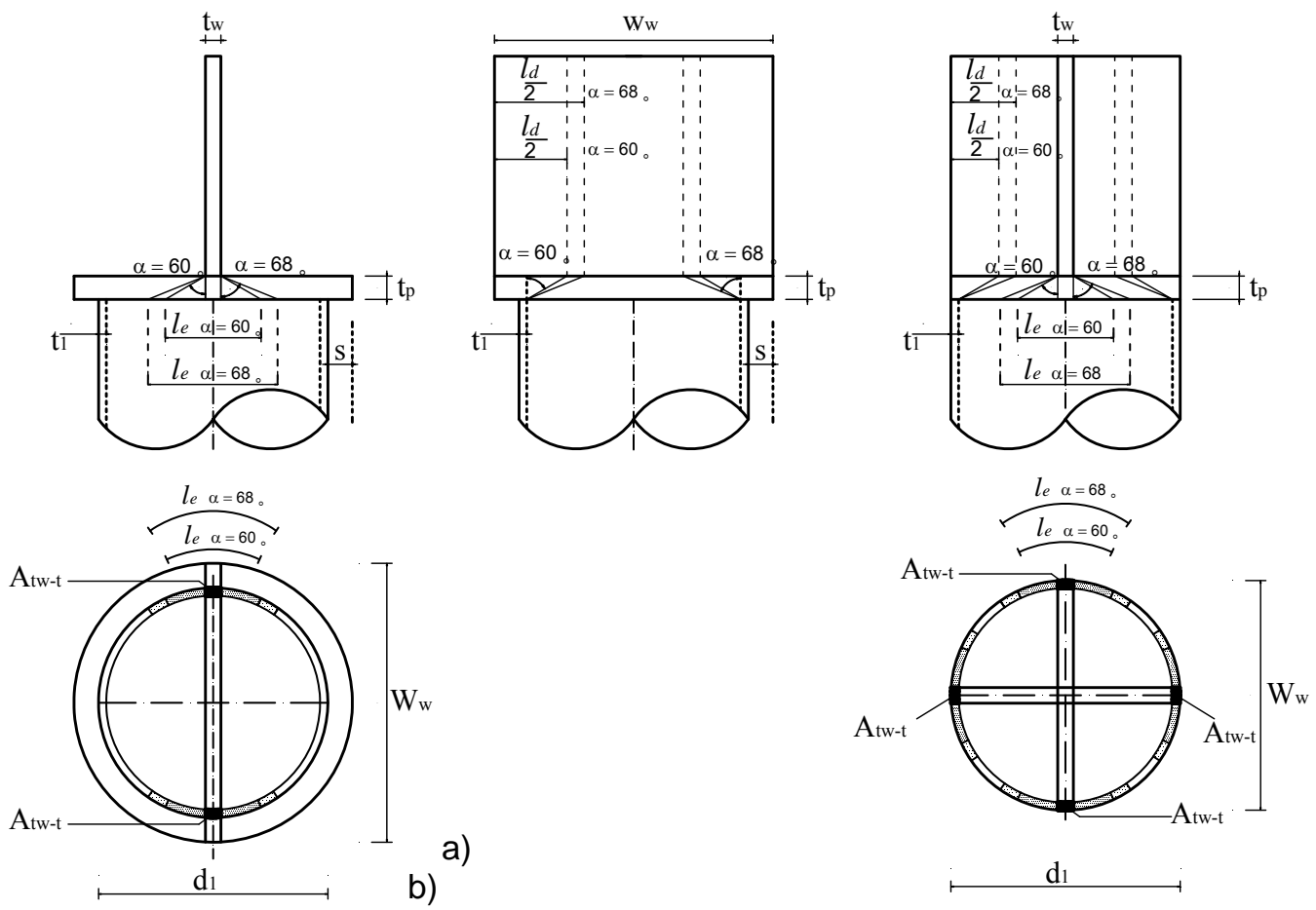

Figure 2. Load Dispersion Mechanism for Tube and Tee Web Resistance for Tee Joints with Diffusion Slopes of $60^{\circ}$ and $68^{\circ}$ for Welded-Tee end Connections with a) One b) Two Tee Webs

If two cross tee webs are used, the stress transfer mechanism changes because the distribution element (i.e. the cap plate) is stiffer. As a consequence, the state of stress within the structural elements is completely different. In fact, the points of contact increase from 2 to 4 , thus new rules need to be introduced for designing these joints. This is remarked in the present work, in which the structural behavior of CHS connection, obtained with one or two cross tee webs, are numerically and experimentally compared. 


\section{DESIGNING WELDED TEE END CONNECTION}

Design Guides for welded tee end connections (Figure 1a) with one tee web are included in some International Specifications [3]. They are the results of several researches such as those developed by Kitipornchai and Traves [6] and by Stevens and Kitipornchai [7] at Queensland University (Australia). These works were taken as references by the American Institute for Steel Construction [3] (see Commentary to section "k"). Before 1989, design guidelines for "welded-tee end connections" for circular hollow tubes were reported in the Specifications of the American Institute of Steel Construction [8] and in design codes of Australian Standard Association [9]. In both the codes, stresses in the tube are calculated assuming a load diffusion slope of $60^{\circ}$ within the thickness of the cap plate (Figure 2a). However, according to other authors [4-8], the assumption of a distribution slope equal to 2.5:1 [2] have to be used and therefore the diffusion angle of $68^{\circ}$ is used. Independently from the diffusion angle, the effective length for load diffusion $l_{e}$ can be computed by the following equation:

$$
\mathrm{l}_{\mathrm{e}}=\mathrm{t}_{\mathrm{w}}+\mathrm{m} \cdot \mathrm{t}_{\mathrm{p}}
$$

where $t_{\mathrm{w}}=$ thickness of the tee web; $t_{\mathrm{p}}=$ thickness of the cap plate; $\mathrm{m}=$ coefficient (if the diffusion angle is $68^{\circ}, \mathrm{m}=5$; if the diffusion angle is equal to $60^{\circ}, \mathrm{m}=3.5$ ). Consequently it is possible to define the design load resistance $\mathrm{N}_{1}$ for the tube of the CHS connection:

$\mathrm{N}_{1}=2 \cdot \mathrm{f}_{\mathrm{y} 1} \cdot \mathrm{t}_{1} \cdot \mathrm{l}_{\mathrm{e}}$

where $f_{\mathrm{y} 1}=$ yielding stress of the tube and $t_{1}=$ thickness of the tube. In the Design Guide by Wardenier et al. [2], an equation for designing load of the tee web $\mathrm{N}_{\mathrm{i}}$ is also suggested. It is based on a slope diffusion similar to that adopted for the bearing capacity of the tube (Eq. 2). If the web width and the diameter of the cap plate are the same (and equal to $d_{i}+2 s$ ), the design load $\mathrm{N}_{i}$ may be calculated as:

$$
N_{i}=2 \cdot f_{y w} \cdot t_{w} \cdot\left(t_{1}+m / 2 \cdot t_{p}+s\right)
$$

where $f_{\mathrm{yw}}=$ yielding stress of the tee web; $\mathrm{s}=$ edge distance of a cap plate (i.e. radius of the cap plate minus radius of the tube). The coefficient 2, which appears into the Eqs. 2 and 3, is due to the two areas $A_{t w-t}$ (see Figure 2a) that connect the tee web and the tube. Eq. 3 is only valid for $\mathrm{s} \leq \mathrm{m} / 2 \cdot \mathrm{t}_{\mathrm{p}}$ and the maximum design load for the tee web results:

$\mathrm{N}_{\mathrm{i}, \max }=2 \cdot \mathrm{f}_{\mathrm{yw}} \cdot \mathrm{t}_{\mathrm{w}} \cdot\left(\mathrm{t}_{1}+\mathrm{m} \cdot \mathrm{t}_{\mathrm{p}}\right)$

If two cross tee webs are used (see Figure $2 \mathrm{~b}$ ), there are 4 areas of contact $\left(\mathrm{A}_{\mathrm{tw}-\mathrm{t}}\right)$ and therefore the efficiency of the joint increases. However, as confirmed by the experimental analysis reported in the next section, Eqs. 2-3 cannot be simply extended to designing the connection depicted in Figure $2 b$. 


\section{EXPERIMENTAL ANALYSIS}

\subsection{Specimens Description}

The structural behavior of one tee web connection in tension (Figure 3a), is experimentally compared with that made by two cross tee webs (Figure 3b). The specimens, named $\mathrm{M}_{1} 9 \mathrm{x} 6$ and $\mathrm{M}_{2} 9 \mathrm{x} 6$, are respectively shown in Figures $3 \mathrm{c}$ and $3 \mathrm{~d}$. They consist of welded tee joints, having $\mathrm{s}=0$, whose dimensions (see Table 1) are chosen in accordance with those tested by Kitipornchai and Traves [6]. In particular, the tube has a diameter of $88.9 \mathrm{~mm}$, a length of $350 \mathrm{~mm}$ and a thickness of $3 \mathrm{~mm}$. The ratio between the diameter and the thickness of the tube is a value commonly used in steel construction.

One of the ends of the specimen $M_{1} 9 \times 6$ is made with a cap plate and a tee web, having a thickness of 9 and $6 \mathrm{~mm}$, respectively. In this manner, the ratio between the thicknesses of the cap plate $t_{p}$ and tube diameter $d_{1}$ is equal to 0.1 . The opposite end is designed to be stronger. More precisely, a thick plate $(12 \mathrm{~mm}$ ) slotted into the tube for a length of $150 \mathrm{~mm}$ (see Figure 3a) is welded as depicted in Figure 1c. The distance between the two ends, measured along the tube, is equal to $200 \mathrm{~mm}$. The specimen named $\mathrm{M}_{2} 9 \times 6$ (Figure 3b) is assembled with two cross tee webs (thickness $6 \mathrm{~mm}$ ) and with a cap plate (thickness of $9 \mathrm{~mm}$ ). To simplify the clamping jaw action, only a single tee web is extended of $135 \mathrm{~mm}$, and its thickness is doubled in order to ensure the same resisting section area.

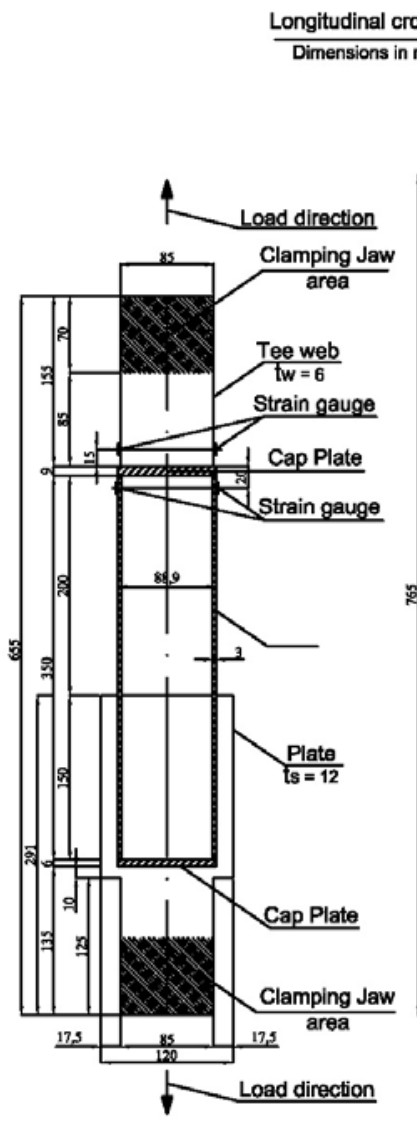

a)

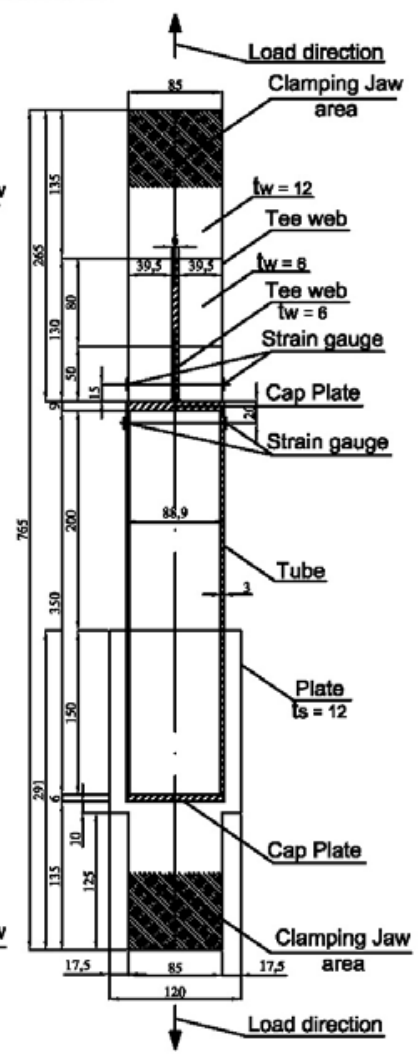

b)

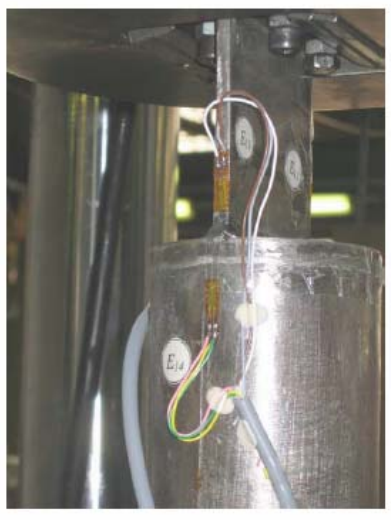

c)

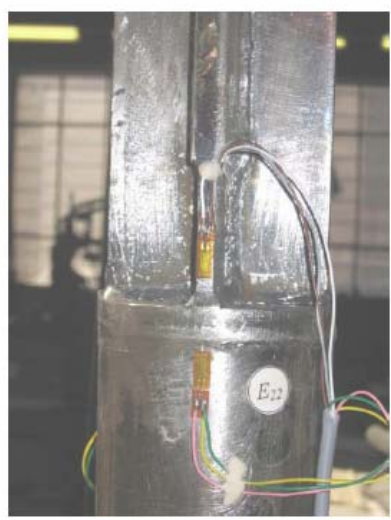

d)

Figure 3. Test Specimens Prepared in the Laboratory with a), c) One Tee Web $M_{1} 9 \times 6$ and b), d) Two Tee Webs $M_{2} 9 \times 6$ 
Table 1. Geometrical Characteristics of Experimental Tests

\begin{tabular}{ccc|ccc|ccccc} 
& \multicolumn{2}{c|}{ Tube } & \multicolumn{4}{c|}{ Cap Plate } & \multicolumn{5}{c}{ Tee Web } \\
\cline { 2 - 10 } & $\begin{array}{c}\mathrm{d}_{1} \\
{[\mathrm{~mm}]}\end{array}$ & $\begin{array}{c}\mathrm{t}_{1} \\
{[\mathrm{~mm}]}\end{array}$ & $\begin{array}{c}\mathrm{W}_{\mathrm{p}} \\
{[\mathrm{mm}]}\end{array}$ & $\begin{array}{c}\mathrm{t}_{\mathrm{p}} \\
{[\mathrm{mm}]}\end{array}$ & $\begin{array}{c}\mathrm{t}_{\mathrm{p}} / \mathrm{d}_{1} \\
{[-]}\end{array}$ & $\begin{array}{c}\mathrm{W}_{\mathrm{w}} \\
{[\mathrm{mm}]}\end{array}$ & $\begin{array}{c}\mathrm{W}_{\mathrm{w}} / \mathrm{d}_{1} \\
{[\mathrm{~mm}]}\end{array}$ & $\begin{array}{c}\mathrm{t}_{\mathrm{w}} \\
{[\mathrm{mm}]}\end{array}$ & $\begin{array}{c}\mathrm{t}_{\mathrm{w}} / \mathrm{d}_{1} \\
{[\mathrm{~mm}]}\end{array}$ & $\begin{array}{c}\text { Area } \\
{\left[\mathrm{mm}^{2}\right]}\end{array}$ \\
\hline $\mathrm{M}_{1} 9 \times 6$ & 88.9 & 3 & 88.9 & 9 & 0.10 & 85 & 0.96 & 6 & 0.07 & 510 \\
\hline $\mathrm{M}_{2} 9 \times 6$ & 88.9 & 3 & 88.9 & 9 & 0.10 & 85 & 0.96 & 6 & 0.07 & 984 \\
\hline
\end{tabular}
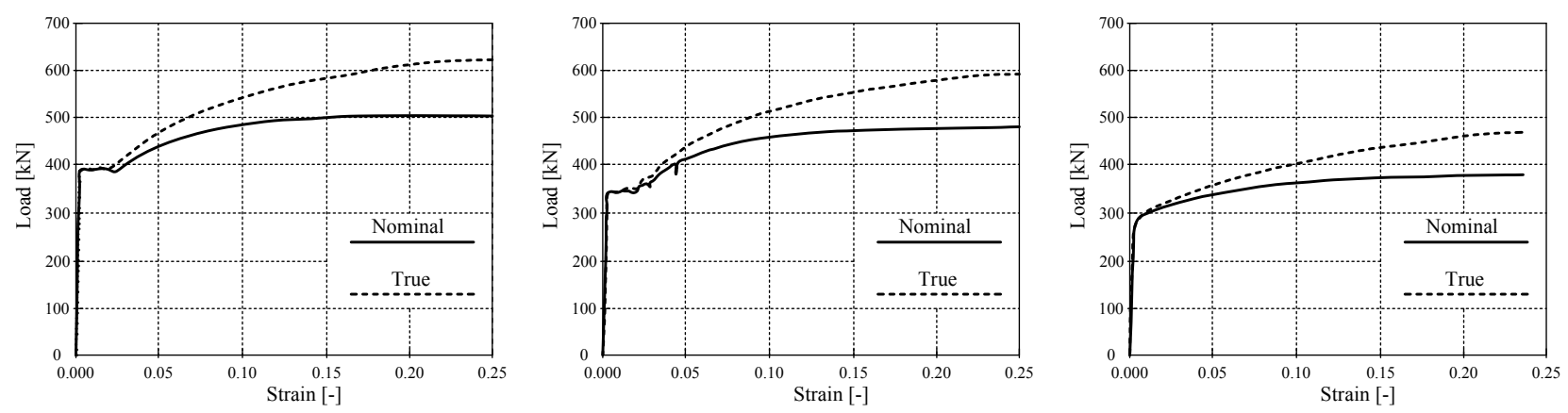

Figure 4. Stress-Strain Curve and Nominal Stress Strain Curve for

a) Cap Plate, b) Tee Web, c) Tube

The tube is cold formed whereas the cap plate and the tee webs are obtained by hot rolling. The mechanical properties of the elements are listed in Table 2. They are measured from the stress strain relationships (see Figure 4) from coupon tests. All the weldings are arc welded by means of a semi automatic procedure. Double bevel tee welding is used between the tee webs and the cap plate. A single vee corner connection is used to join the cap plate and the tube.

Quasi static loads are applied to the specimens (Figures 3a and 3b) through a MTS machine having a bearing capacity of $1000 \mathrm{kN}$. A displacement control procedure with a rate of $7.8 \cdot 10^{-4} \mathrm{~mm} / \mathrm{s}$ is imposed during the elastic stage. This rate is increased to $5 \cdot 10^{-2}$ as soon as the nonlinear response becomes evident. The test, conducted up to the global collapse of the joint, were performed at the Department of Structural and Geotechnical Engineering of Politecnico di Torino (Italy).

In order to measure the local longitudinal strains, two couples of strain gauges (width $6 \mathrm{~mm}$, length $10 \mathrm{~mm}$, and maximum strain capacity 1\%) are applied on the surfaces of each specimens. One couple is positioned on tee web at a distance of $15 \mathrm{~mm}$ from the cap plate (see Figures $3 \mathrm{a}-\mathrm{b}$ ), while the other couple is positioned on the external surface of the tube at a distance of $20 \mathrm{~mm}$ from the cap plate.

Table 2. Mechanical Properties of Materials for the Elements

\begin{tabular}{c|c|c|c|c|} 
& $\begin{array}{c}\text { Yeld stress } \\
{[\mathrm{MPa}]}\end{array}$ & $\begin{array}{c}\text { Ultimate stress } \\
{[\mathrm{MPa}]}\end{array}$ & $\begin{array}{c}\text { Ultimate deformation } \\
{[\%]}\end{array}$ & $\begin{array}{c}\text { Elastic modulus } \\
{[\mathrm{MPa}]}\end{array}$ \\
\hline Tee web & 343 & 476 & 34 & 204500 \\
\hline Tube & 287 & 378 & 27.3 & 199400 \\
\hline Cap plate & 391 & 502 & 33.2 & 202700 \\
\hline
\end{tabular}




\section{TEST RESULTS}

The results of the tests, in terms of load-total displacement, are reported in Figure 5. For the specimen $\mathrm{M}_{1} 9 \mathrm{x} 6$ with one tee web, a yielding load (i.e. deviation from the linear behavior as the ideal point corresponding to the load level where the linear and the plastic branch converge) equal to $150 \mathrm{kN}$ and an ultimate load of $193 \mathrm{kN}$ are observed. In the same way, for the specimen $\mathrm{M}_{2} 9 \times 6$, having two cross tee webs, the global yielding is reached $210 \mathrm{kN}$ while the collapse occurs at $263 \mathrm{kN}$. The specimens show different failure mechanisms. $\mathrm{M}_{1} 9 \mathrm{x} 6$ collapses after the cracking of the tee web close to the cap plate (Figure 6a). At the failure, the total elongation of the specimen is $10 \mathrm{~mm}$. The tee web shows a slight necking and the cap plate presents a large curvature.

The specimen named $\mathrm{M}_{2} 9 \times 6$ reaches the ultimate state with an elongation of about $40 \mathrm{~mm}$ (see Figure 5b) which involved the whole tube and produces a necking on it. As a result, a large pseudo-plastic stage is showed in Figure 5. Moreover, at the collapse, a crack on the interface between the cap plate and the tube appears (Figure 6b). In the same structural element, the increase of mechanical strength (about 36\%) can be ascribed to a tightening of the cap plate, and, consequently, to a more uniform stress within the tube. However in this case, the ultimate and yielding loads do not double with respect to those measured in one tee web joint, although the cross sectional area is doubled, as it could be obtained with the application of the rules of Eq. 2 and 3 of the design code. It is also probably due to a more restrained condition for the joint with two tee webs that determine a multiaxial state of stress and a consequent reduction of the plastic resources in the critical zone. In Figure 5 the increment of load level within the first millimeters of deformation, that can be associated with the joint, show a lower increase of load level for the specimen $\mathrm{M}_{2} 9 \times 6$ if compared to the specimen $\mathrm{M}_{1} 9 \times 6$.

The diagrams loads vs. strain, measured by the strain gauges glued on the specimen M19x6, are reported in Figure 7a. In this Figure, the continuous curve reproduces the average strain of the tee web, whereas the dashed line indicates the average strains of the tube. Similarly, for the specimen $\mathrm{M}_{2} 9 \mathrm{x} 6$ the load-strain curves of the tube (dashed line) and the tee web (continuous line) are depicted in Figure 7b. In these Figures a different structural behavior appears. While in the specimen $M_{1} 9 \times 6$ the nonlinear behavior of the tube and the tee web simultaneously occurs, in the specimen $\mathrm{M}_{2} 9 \times 6$ the deviation from the linearity begins initially in the tube for a load (about 20\%) lower than the yielding load of the tee web.

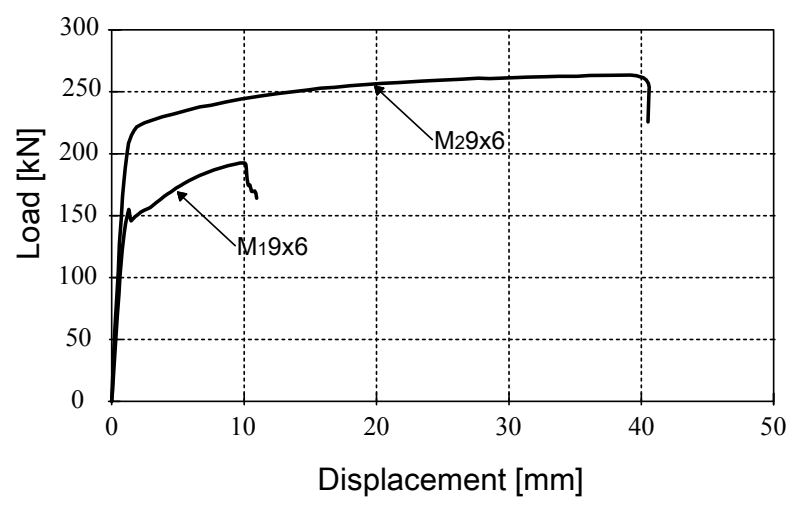

Figure 5. Load-displacement Curves for Tests $M_{1} 9 \times 6$ and $M_{2} 9 \times 6$ 


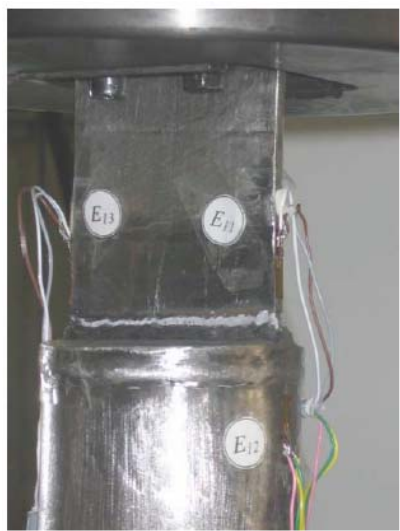

a)

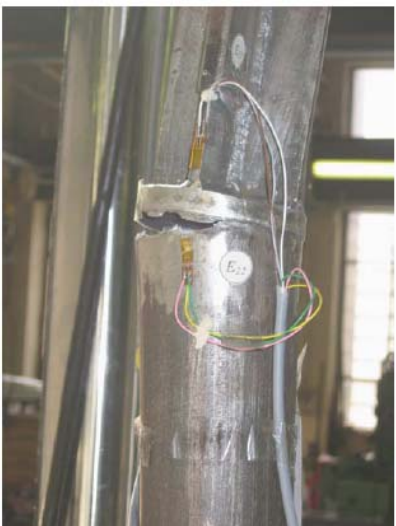

b)

Figure 6. Detail of the Rupture in the Two Test Specimens:

a) Test with One Tee Web, b) Test with Two Tee Webs

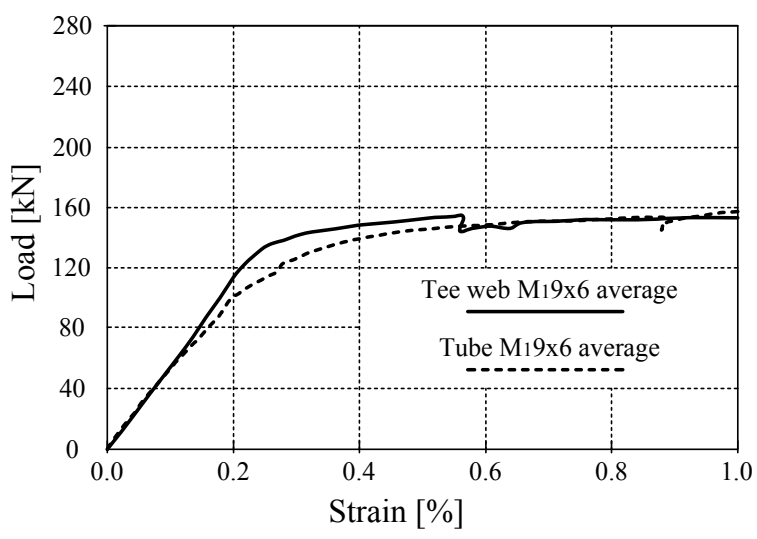

a)

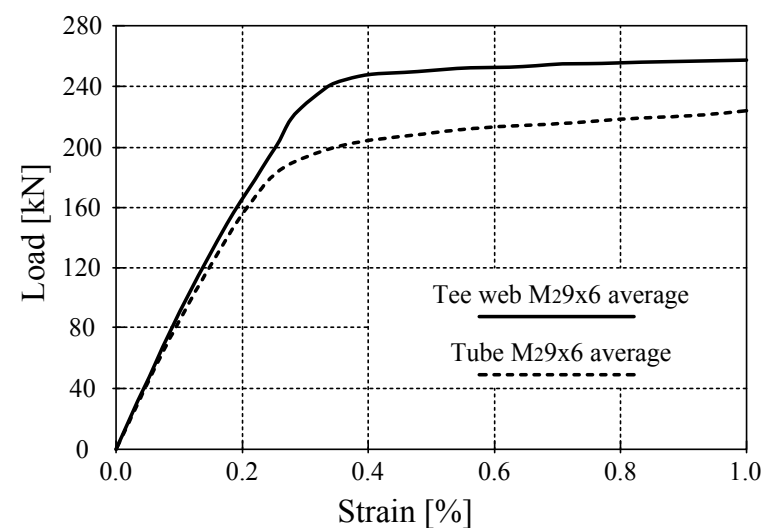

b)

Figure 7. Load-deformation Curves Recorded by the Strain Gauges Placed on the Tube and on the Tee Web for a) One Tee Web Joint and b) Two Tee Webs Joint

\section{NUMERICAL MODEL}

Together with the experimental tests, the structural behavior of the joints is modeled with a finite element analysis (FEM). Tri-dimensional isoparametric elements, having 20 nodes, three translational degrees of freedom, and able to encompass large strains, are adopted by using ADINA v8.3 program [10]. Nominal stresses and strains in the tee webs, the cap plate, and the tube, are defined by the following equations:

$$
\begin{aligned}
& \varepsilon_{r}=\ln \left(1+\varepsilon_{n}\right) \\
& \sigma_{r}=\sigma_{n}\left(1+\varepsilon_{n}\right)
\end{aligned}
$$

with

$\varepsilon_{\mathrm{n}}=\frac{\mathrm{I}-\mathrm{I}_{0}}{\mathrm{I}_{0}}$ 
Where $\varepsilon_{\mathrm{n}}, \sigma_{\mathrm{n}}=$ nominal strains and stresses, $\varepsilon_{\mathrm{r}}, \sigma_{\mathrm{r}}=$ true strains and stresses, $1_{0}=$ reference length, and 1 = final length. The curves of nominal and true stress vs. nominal and true strain, obtained with Eq. 5 and 6 are reported in Figure 4. The nonlinear analysis is based on the Von-Mises flow rule with the isotropic hardening assumption; the rupture plastic strain corresponds to the effective plastic strain at the last point input for the stress strain curve for the materials (Figure 4).

Due to the double symmetry of joint with respect to load and constraints, only a quarter of the entire structure is modeled (Figure 8). In particular, the finite element mesh regards the tee webs, the cap plate and a part of the tube. The analysis is performed by imposing displacements on the free end of each model and computing the corresponding tensile load from the reaction. The FEM models are shown in Figure $8 a$ for the specimen $M_{1} 9 x 6$ and in Figure $8 b$ for the specimen $M_{2} 9 x 6$.

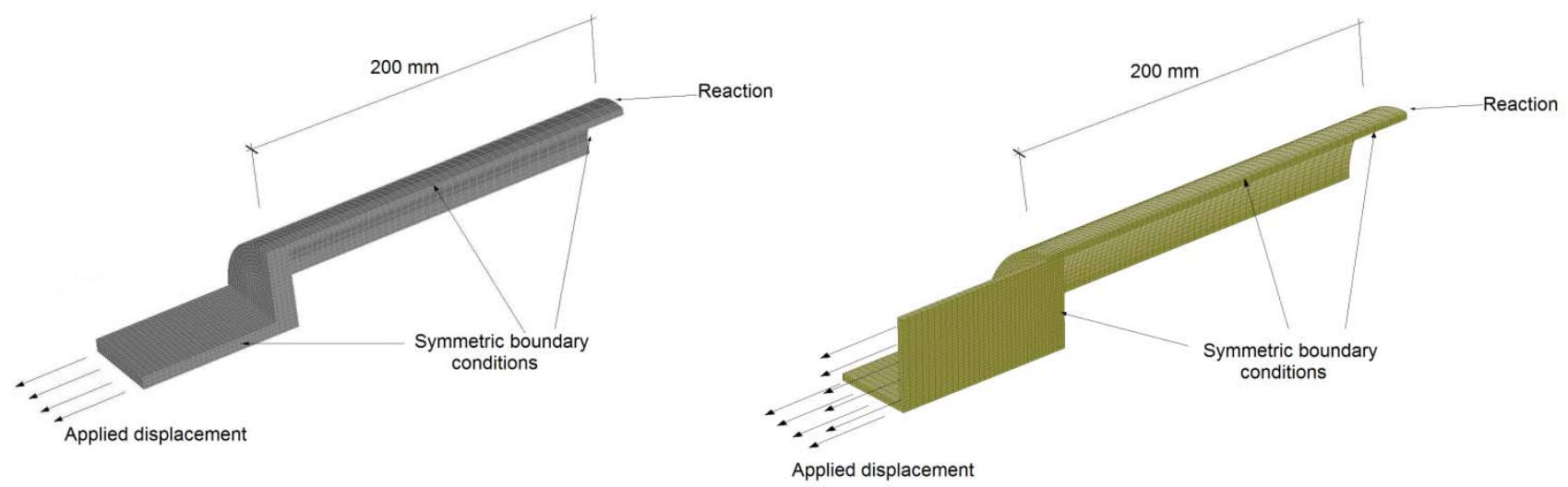

Figure 8. Boundary Conditions for the Model

a) FE1 that Simulates Test $M_{1} 9 \times 6$ and b) FE2 that Simulates $M_{2} 9 \times 6$

The results of the numerical analysis, in terms of load displacement, are called FE1 and FE2 for the specimens $M_{1} 9 \times 6$ and $M_{2} 9 \times 6$, respectively. They are reported in Figure 9, whereas Figure 10 shows some images of the plastic strains. For the specimen $M_{1} 9 \times 6$ the measured load displacement diagram is in good agreement with the numerical results of the analysis FE1. From these diagrams, the nonlinear behavior of the whole joint appears at $125 \mathrm{kN}$. However, if lower loads are applied, the joint is in the linear elastic regime, although the edges of the tee web show plastic deformations at the connection with the cap plate. This is evident in Figure 10a, where the plastic strain distribution of step I, which corresponds to a load $\mathrm{N}=100 \mathrm{kN}$ (see Figure 9) is reported. For loads higher than $125 \mathrm{kN}$ (step II in Figure 10a) a more extended plastic zone can be observed between the tee web and the cap plate, which is also subjected to bending action. The failure (step III in Figure 10a), which appears at $\mathrm{N}=179 \mathrm{kN}$, is finally localized around the connection between tee web and cap plate, as obtained in the experimental results (Figure 6a).

In the case of the specimen $\mathrm{M}_{2} 9 \times 6$, the load-displacement curve obtained with the numerical analysis (model FE2), is able to predict with good accuracy the yielding and the collapse loads experimentally measured (Figure 9). The nonlinear behavior is evident for $\mathrm{N}>200 \mathrm{kN}$, even if plastic zones are generated for lower loads (step I in Figure 10b). However, with respect to FE1 (step I in Figure 10a), these zones are located in few elements at the connection between the tee webs and the cap plate. If the load is increased (step II in Figure 10b) plastic strains affect a larger area. Nevertheless, due to a more uniform distribution, maximum strains are lower than those obtained with FE1 analysis (step II in Figure 10a). As illustrated in Figure 10b, during step III, wide plastic strains affect both the interface between cap plate and tee webs, and between tube and cap plate. In these zones the failure might occur. This explains the discrepancy between the numerical results of FE2, in which a failure on the interface between tee web and cap plate occurs 
(load N $=247 \mathrm{kN}$, step III in Figure 10b) and the observed failure in the tube (Figure 4b). It is sufficient a little variations of the material characteristics or small and localized defects (e.g., an incomplete penetration of the weld between cap plate and tube) to obtain one of the possible failure mechanisms.

In Figure 11a the strains measured by the gauges glued on the tube of each specimen are compared with the FEM results. In both the cases, FE1 and FE2 analyses provide, respectively, a good approximation of the local strains in the tube. In the same way, the strains measured on the tee webs are compared with those in Figure $11 \mathrm{~b}$ with those numerically computed. In all the diagrams of Figure 11, the higher load bearing capacity of the joint $\mathrm{M}_{2} 9 \times 6$ is clearly evident.

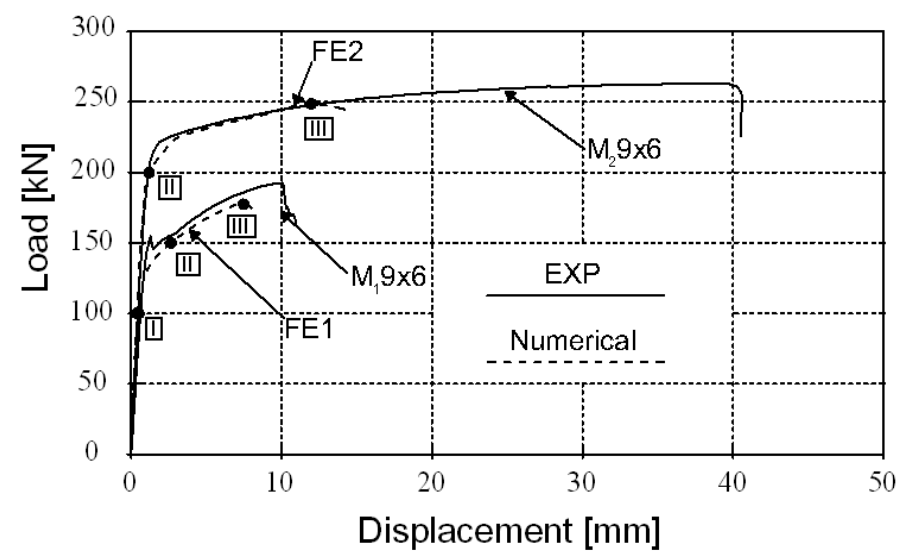

Figure 9. Load-displacement Curves for Tests and Numerical Models

(Step I)

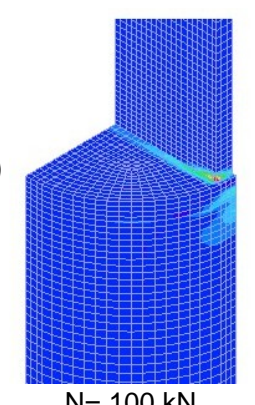

(Step I)

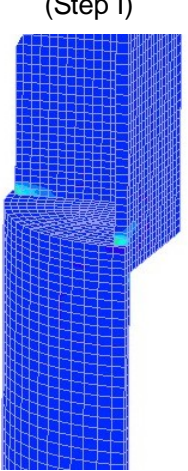

$\mathrm{N}=100 \mathrm{kN}$

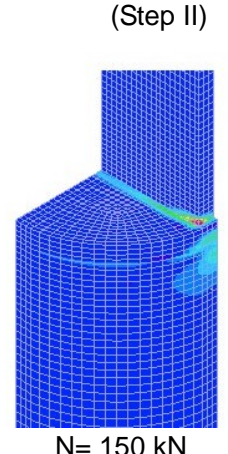

(Step II)

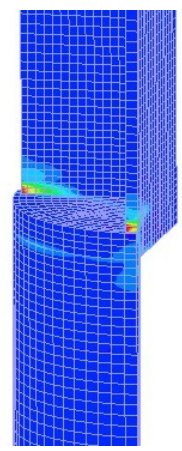

$\mathrm{N}=200 \mathrm{kN}$
(Step III)

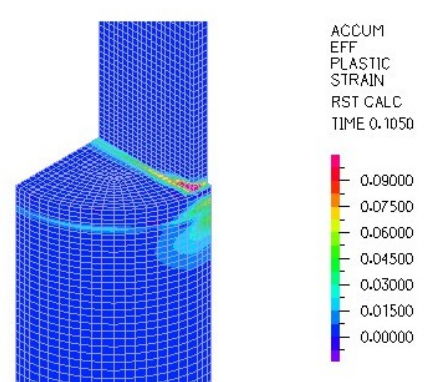

$\mathrm{N}=179 \mathrm{kN}$

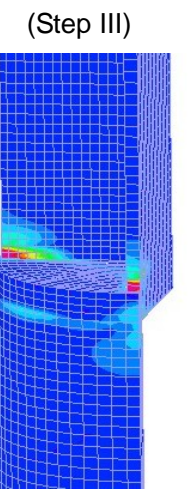

$\mathrm{N}=247 \mathrm{kN}$

Figure 10. Plastic Strain Concentration for Increasing Load a) One Tee Web Model and b) Two Cross Tee Webs Model 


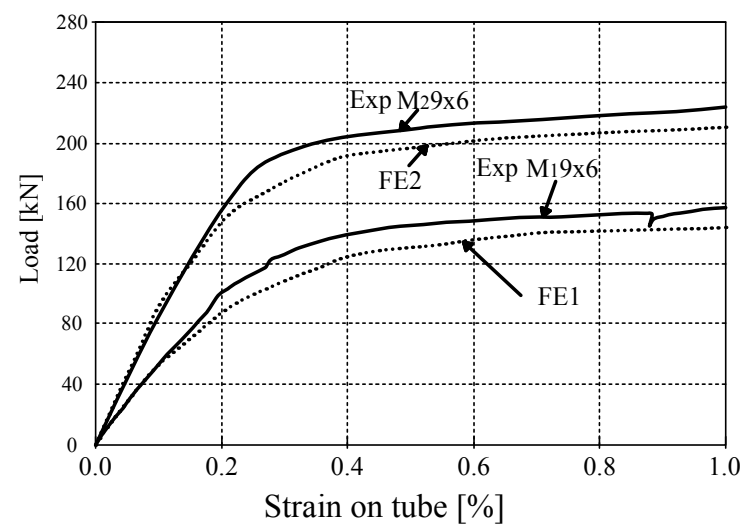

a)

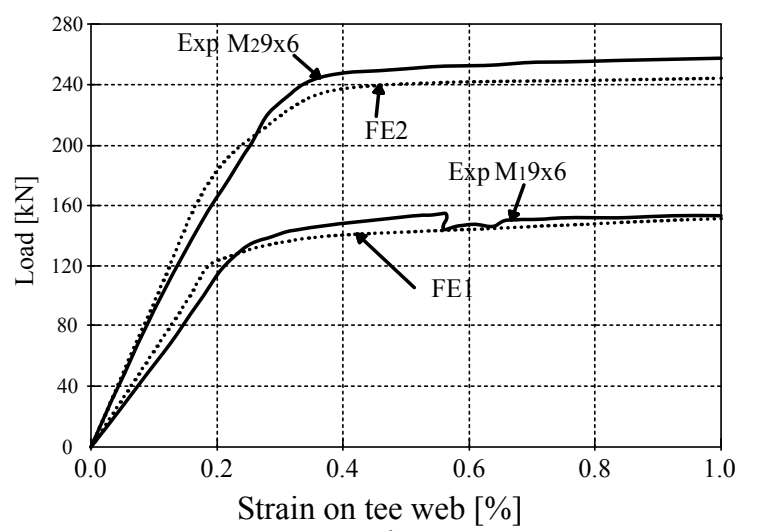

b)

Figure 11. Comparison between the Numerical and Experimental Results of the Strain Gauge Readings a) on the Tubes and b) on the Tee Web of the Specimens and the Fem Models

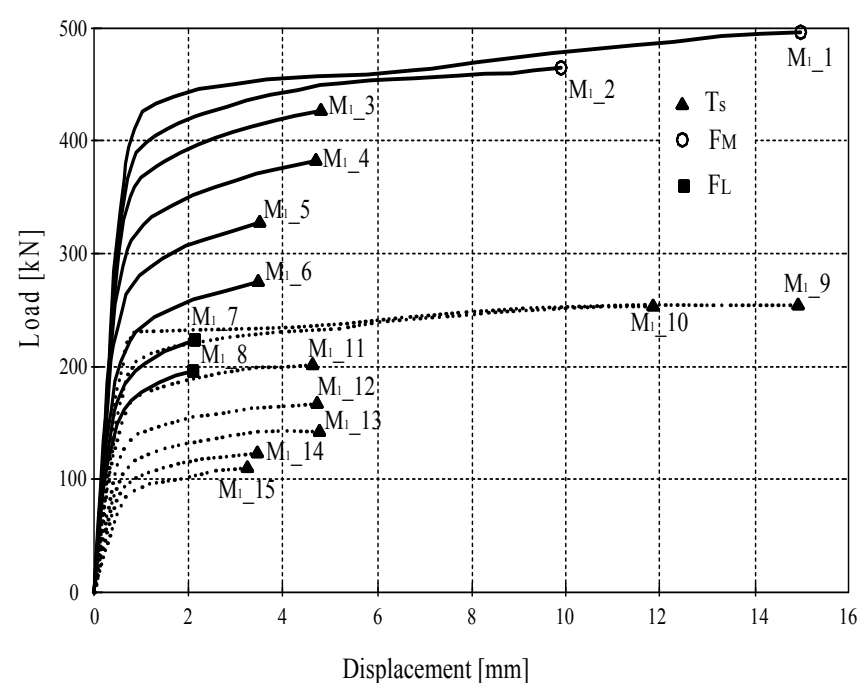

a)
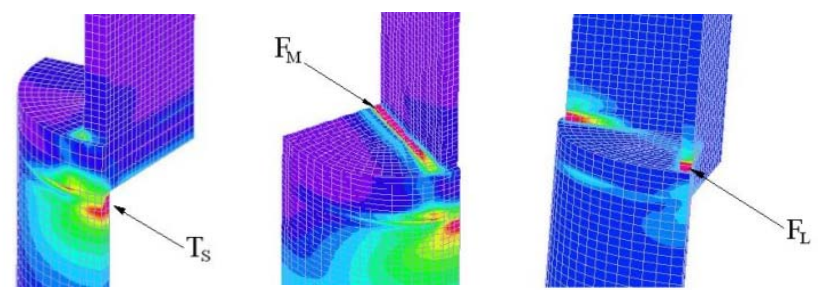

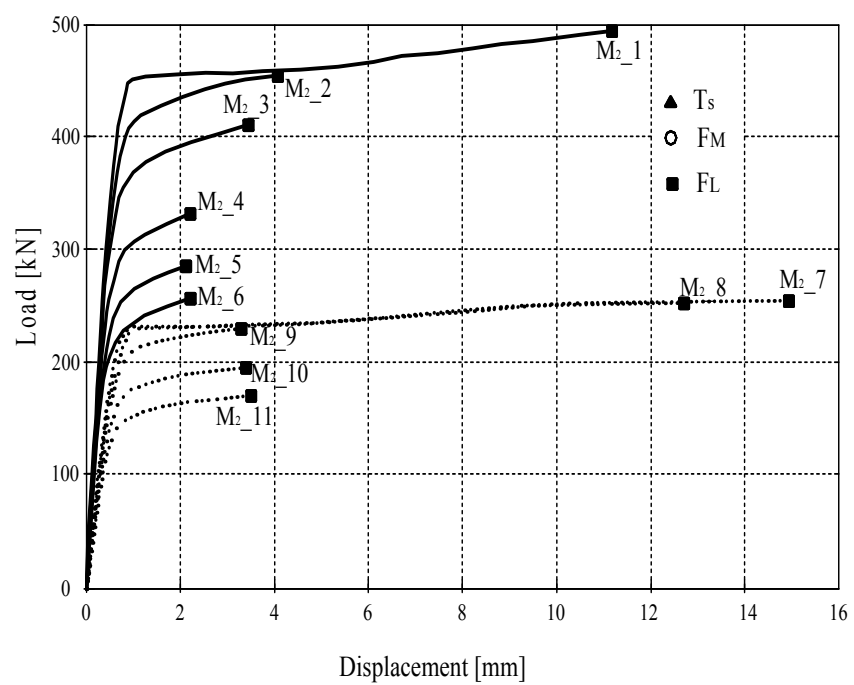

b)
$\mathrm{T}_{\mathrm{s}}=$ Initiation of crack on the tube towards the tee web

$\mathrm{FM}=$ Intermediate initiation of crack between the tee web and the cap plate $\mathrm{FL}=$ Initiation of Crack on the lateral edge of the tee web

Figure 12. Load Displacement Curves and Type of Crack Initiation for the Models of Parametric Analysis with a) One Tee Web and b) Two Tee Webs; c) Point of Rupture Initiation 


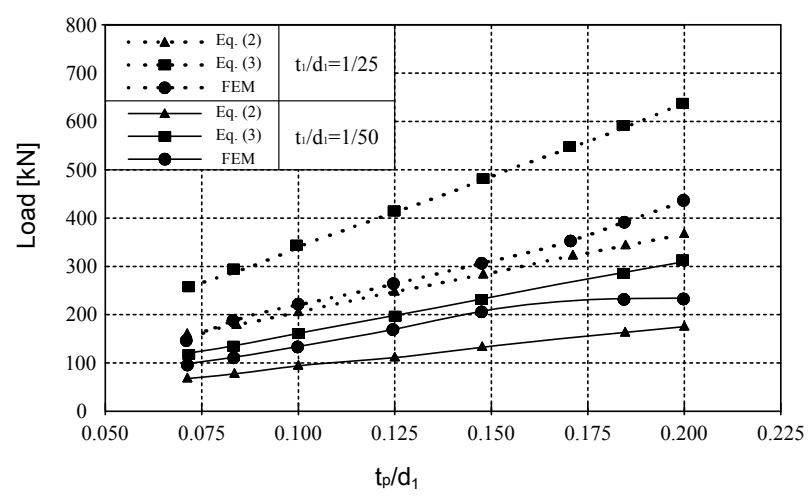

a)

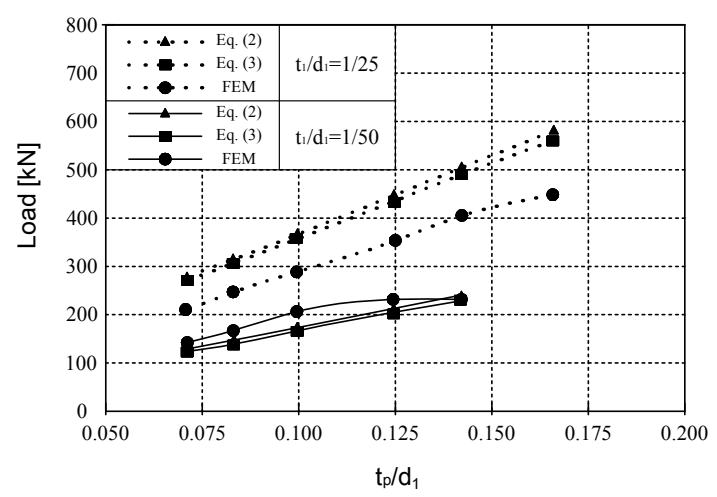

b)

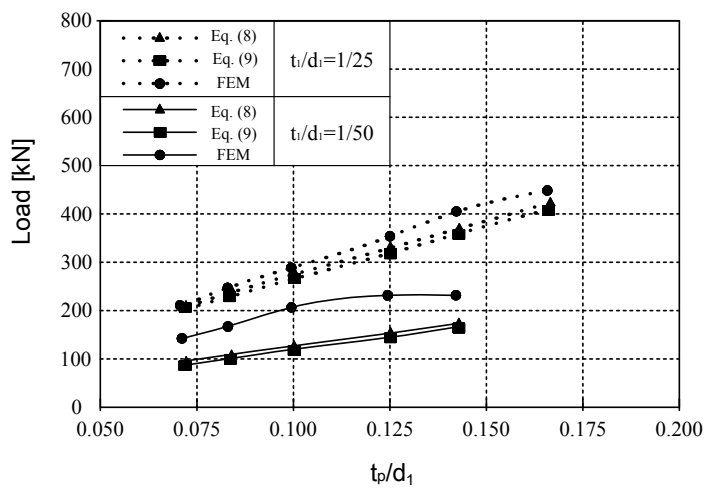

c)

Figure 13. Loads of Non-linearity Behavior for Joints for Models with

a) One Tee Web $\left(\alpha=68^{\circ}\right)$, b) Two Tee Webs $\left(\alpha=68^{\circ}\right)$ and c) Two Tee Webs $\left(\alpha=60^{\circ}\right)$

\section{PARAMETRIC ANALYSIS AND DESIGN FORMULAE}

Starting from the good agreement between the test results and the numerical evaluation of the bearing capacity a parametric analysis is performed. By means of the numerical models previously introduced, it is possible to analyze the influence of some parameters such as the ratios $t_{1} / d_{1}$ and $t_{p} / d_{1}$ on the mechanical response of the joints with one or two tee webs. These ratios were also considered in the analysis made by Kitipornchai and Traves [6] and by Stevens and Kitipornchai [7] for one tee web joints.

If the tube diameter is fixed at $d_{1}=100 \mathrm{~mm}$, the ratios $t_{1} / d_{1}$ and $t_{p} / d_{1}$ for the joint with one tee web (named $\mathrm{M}_{1}$ ) have been varied as listed in Table 3. In the same manner, for joints with two tee webs (named $\mathrm{M}_{2}$ ) the parameters have been modified according to Table 4. In total, 15 models with one tee web (named from $\mathrm{M}_{1} 1$ to $\mathrm{M}_{1} 15$ ) and 11 models with two tee webs (named from $\mathrm{M}_{2} 1$ to $\mathrm{M}_{2} 11$ ) have been analyzed. For all the elements the thicknesses of the tee webs are designed in order to have a cross sectional area higher than the cross-sectional area of the tube of about $15 \%$. An area increase like that is generally used in bolted lap joints to compensate the reduction produced by the holes.

The ratios $t_{1} / d_{1}=1 / 25$ and $t_{1} / d_{1}=1 / 50$ corresponds to tubular elements with a medium and thin thickness, respectively. The numerical results in term of load displacement curves are reported in Figure 12a (models $\mathrm{M}_{1}$ ) and in Figure $12 \mathrm{~b}$ (models $\mathrm{M}_{2}$ ). They are obtained by assuming the constitutive relationship of materials of Figure 4. In the same Figures, different points of failure are also reported. They are named $\mathrm{T}_{\mathrm{s}}, \mathrm{F}_{\mathrm{M}}$, and $\mathrm{F}_{\mathrm{L}}$, if the ultimate strain is reached respectively in the tube, in the internal part of the tee web, or on the edge of the tee web (see Figure 12c). 
Table 3. Thicknesses for One Tee Web Joints with $d_{1}$ Equal to $100 \mathrm{~mm}$

\begin{tabular}{c|c} 
Joint & $\mathrm{t}_{\mathrm{p}} / \mathrm{d}_{1}$ \\
\hline $\mathrm{M}_{1 \_} 1$ & $1 / 5$ \\
\hline $\mathrm{M}_{1 \_} 2$ & $18.5 / 100$ \\
\hline $\mathrm{M}_{1 \_} 3$ & $17.1 / 100$ \\
\hline $\mathrm{M}_{1 \_} 4$ & $14.8 / 100$ \\
\hline $\mathrm{M}_{1 \_} 5$ & $1 / 8$ \\
\hline $\mathrm{M}_{1 \_} 6$ & $1 / 10$ \\
\hline $\mathrm{M}_{1 \_} 7$ & $1 / 12$ \\
\hline $\mathrm{M}_{1 \_} 8$ & $1 / 14$ \\
\hline $\mathrm{t}_{1} / \mathrm{d}_{1}=1 / 25$ & $\mathrm{t}_{\mathrm{w}}=14.7 \mathrm{~mm}$
\end{tabular}

\begin{tabular}{c|c} 
Joint & $\mathrm{t}_{\mathrm{p}} / \mathrm{d}_{1}$ \\
\hline $\mathrm{M}_{1 \_} 9$ & $1 / 5$ \\
\hline $\mathrm{M}_{1 \_} 10$ & $18.5 / 100$ \\
\hline $\mathrm{M}_{1 \_11}$ & $14.8 / 100$ \\
\hline $\mathrm{M}_{1 \_} 12$ & $1 / 8$ \\
\hline $\mathrm{M}_{1 \_} 13$ & $1 / 10$ \\
\hline $\mathrm{M}_{1 \_14}$ & $1 / 12$ \\
\hline $\mathrm{M}_{1 \_} 15$ & $1 / 14$ \\
\hline \multicolumn{2}{|c}{} \\
$\mathrm{t}_{1} / \mathrm{d}_{1}=1 / 50$ & $\mathrm{t}_{\mathrm{w}}=7.4 \mathrm{~mm}$
\end{tabular}

Table 4. Thicknesses for two tee web joints with $\mathrm{d}_{1}$ equal to $100 \mathrm{~mm}$

\begin{tabular}{c|c} 
Joint & $\mathrm{t}_{\mathrm{p}} / \mathrm{d}_{1}$ \\
\hline $\mathrm{M}_{2 \_} 1$ & $1 / 6$ \\
\hline $\mathrm{M}_{2 \_} 2$ & $1 / 7$ \\
\hline $\mathrm{M}_{2 \_} 3$ & $1 / 8$ \\
\hline $\mathrm{M}_{2 \_} 4$ & $1 / 10$ \\
\hline $\mathrm{M}_{2 \_} 5$ & $1 / 12$ \\
\hline $\mathrm{M}_{2 \_} 6$ & $1 / 14$ \\
\hline $\mathrm{t}_{1} / \mathrm{d}_{1}=1 / 25$ & $\mathrm{t}_{\mathrm{w}}=7.7 \mathrm{~mm}$
\end{tabular}

\begin{tabular}{c|c} 
Joint & $\mathrm{t}_{\mathrm{p}} / \mathrm{d}_{1}$ \\
\hline $\mathrm{M}_{2} \_$ & $1 / 7$ \\
\hline $\mathrm{M}_{2 \_} 8$ & $1 / 8$ \\
\hline $\mathrm{M}_{2 \_} 9$ & $1 / 10$ \\
\hline $\mathrm{M}_{2 \_} 10$ & $1 / 12$ \\
\hline $\mathrm{M}_{2} \_11$ & $1 / 14$ \\
\hline
\end{tabular}

$\mathrm{t}_{1} / \mathrm{d}_{1}=1 / 50 \quad \mathrm{t}_{\mathrm{w}}=3.8 \mathrm{~mm}$

Increasing the thickness of the cap plate, both the ultimate and yielding loads increase. The presence of two tee webs determines a more uniform stress pattern in the tubes and consequently an increase of their efficiency. For models with two tee webs, the failure is always located on the tee web (close to the cap plate), whereas for joints with one tee web it generally affects the tube, even if in the models $\mathrm{M}_{1} 1, \mathrm{M}_{1} 2, \mathrm{M}_{1} 7$, and $\mathrm{M}_{1} 8$ the concentration of plastic strains regards the tee web.

The yielding loads evaluated with the FEM analysis and those obtained with Eqs. 2 and 3 are compared in Figure 13 for models with one tee web (Figure 13a) and two tee webs (Figure 13b). All the curves are grouped according to the different thicknesses $\left(t_{1} / d_{1}=1 / 25 \div 1 / 50\right)$.

It is not possible to compare directly the results obtained with model of $\mathrm{M}_{1}$ series with model of $M_{2} 1$ series because they have the same ratios $t_{1} / d_{1}$ and $t_{p} / d_{1}$, but they have different thicknesses $t_{w}$ for the tee webs.

For joints with one tee web, the yielding loads computed with numerical models and design approaches [2] increase with the thickness of the cap plate. Both for thick $\left(t_{1} / d_{1}=1 / 25\right)$ and thin tubes $\left(t_{1} / d_{1}=1 / 50\right)$, the Eq. 2 provides a design load lower than Eq. 3, and therefore (Eq. 2) rules the load design capacity of the joint (Figure 13a). The ratio between the yielding load value obtained from FEM analysis and that from Eq. 2 is approximately constant for each type of tube. More precisely, for thin tubes, this ratio is almost equal to 1.4, whereas for thicker tubes it reduces to 1.1. For the specimen $\mathrm{M}_{1} 9 \mathrm{x} 6$, the Design Code with Eq. 2 supplies a design load for the tube equal to $87.8 \mathrm{kN}$, whereas the Eq. 3 provides a design load for the tee web equal to $105.0 \mathrm{kN}$; in this case, in the test the failure is located on the tee web. The ratio between the yielding load measured experimentally and that obtained with the Eq. 2 is equal to 1.7. 
Although they were developed for one tee web joints, Eqs. 2 and 3 are here used also in the case of joints made with two cross tee webs. Precisely, they give substantially the same ultimate loads (see Figure 13b). For thin tubes, the ratio between the yielding load of FEM simulations and those obtained from the Eqs. 2 and 3 is constantly equal to 1.1, and reduces to 0.8 for tubes having $\mathrm{t}_{1} / \mathrm{d}_{1}=1 / 25$. Considering the aforementioned ratios, the design approach can underestimate the yielding load for tube with medium thickness $\left(t_{1} / d_{1}=1 / 25\right)$. For the joint $M_{2} 9 x 6$, the design load obtained with the application of Eq. 2 and Eq. 3 are respectively $175.6 \mathrm{kN}$ and $210.0 \mathrm{kN}$ (i.e. twice the values obtained for joints with one tee web). On the contrary the yielding load measured experimentally is only 1.2 times higher than that observed for specimen $\mathrm{M}_{1} 9 \mathrm{x} 6$.

According to the above observations, the design formulae, if applied to one and two tee webs joints, do not provide the same ratio between the measured and predicted values of design load (Eqs. 2 and 3). In order to ensure similar ratios, for joints with two cross tee webs, a load diffusion angle of $60^{\circ}$ (instead of $68^{\circ}$ ) has to be adopted in the Eq. 2 and Eq. 3. In this way, the design load for the specimen $\mathrm{M}_{2} 9 \times 6$ is reduced to $129 \mathrm{kN}$ and the ratio between the experimentally observed yielding load and that predicted is similar to the ratio of $M_{1} 9 x 6$ (value equal to 1.6). Similarly, the ratio between the yielding loads obtained for the fem simulations and the analytical value calculated by means of a diffusion angle $\alpha=60^{\circ}$, in joints with two tee web, result to be almost the same of those obtained for the elements with one tee web and angle $\alpha=68^{\circ}$. This can be clearly seen from Figure 13c in which the new diffusion angle for two tee web joints is used. In other words, the following equations, which can be considered as an extension of Eqs. 2 and 3 for the two tee web joints, give the design loads:

$$
\begin{aligned}
& \mathrm{N}_{1}=4 \cdot \mathrm{f}_{\mathrm{y} 1} \cdot \mathrm{t}_{1} \cdot\left(\mathrm{t}_{\mathrm{w}}+3.5 \cdot \mathrm{t}_{\mathrm{p}}\right) \\
& \mathrm{N}_{\mathrm{i}}=4 \cdot \mathrm{f}_{\mathrm{yw}} \cdot \mathrm{t}_{\mathrm{w}} \cdot\left(\mathrm{t}_{1}+1.75 \cdot \mathrm{t}_{\mathrm{p}}\right)
\end{aligned}
$$

\section{CONCLUSIONS}

Some aspects regarding the structural behavior of joints for welded-tee end connections, made with one or two cross tee webs and subjected to tensile load are investigated in the present paper. According to this study, also supported by both the numerical and experimental results, the following conclusion can be drawn:

- The current codes do not supply effective design rules for CHS welded tee end connections, having two cross tee webs. The structural behavior of such connections is remarkably different from those made with one tee web.

- In the case of two cross tee webs joints, the deformation of the tube is constrained by two orthogonal tee webs welded on the cap plate and then the stress diffusion mechanism is different from joints with one tee web

- The analytical formulae reported in the literature, developed for joints with one tee web, seem to overestimate the design load for tube and tee webs, if applied to two cross tee webs joints.

With the aim of a harmonization between the two different types of joints, in terms of ratios between the design load evaluated by mean of the structural response evaluated during experimental and numerical test, and the design formula, a reduction of the assumed spread angle through the cap plate is introduced for two cross tee web joints design equations. 


\section{REFERENCES}

[1] Wardenier, J., "Hollow Sections in Structural Applications", CIDECT Publication, 2001, pp.199.

[2] Wardenier, J., Kurobane, Y., Packer, J.A., van der Vegte, G.J. and Zhao, X.L., "Design Guide for Circular Hollow Section (CHS) Joints under Predominantly Static Loading", CIDECT Publication, preliminary version, November 2007.

[3] ANSI/AISC 360-05, "Specification for Structural Steel Buildings", Chicago: American Institute of Steel Construction (AISC), 2005.

[4] CAN/CSA-S16-01, "Limit States Design of Steel Structures", Toronto: Canadian Standards Association (CSA), 2001.

[5] Martinez-Saucedo, G., Packer, J.A. and Willibald, S., "Parametric Finite Element Study of Slotted End Connections to Circular Hollow Sections", Engineering Structures, 2006, Vol. 28, pp. 1956-1971.

[6] Kitipornchai, S. and Traves, W.H., "Welded-Tee End Connections for Circular Hollow Tubes", Journal of Structural Engineering, ASCE, 1989, Vol. 115, No. 12, pp. 3155-3170.

[7] Stevens, N.J. and Kitipornchai, S., "Limit Analysis of Welded-Tee End Connection For Hollow Tubes", Journal of Structural Engineering, ASCE, 1990, Vol. 116, No. 9, pp. 2309-2323.

[8] "Specification for the Design, Fabrication and Erection of Structural Steel for Buildings", American Institute of Steel Construction, New York, N.Y., 1978.

[9] AS 1250 Steel Structures Code, Standard Association of Australia, Sydney, 1981.

[10] ADINA Finite Element System for Structures, Release 8.3, Watertown, USA, 2003. 